\title{
Pelatihan Pembukuan Sederhana Untuk Meningkatkan Kinerja Keuangan Pelaku Usaha Di Desa Kebontunggul Kecamatan Gondang Kabupaten Mojokerto
}

\author{
Rina Fariana ${ }^{1}$, Fauziyah ${ }^{2}$, Teguh Purwanto ${ }^{3}$, Bayu Adi ${ }^{4}$ \\ ${ }^{1234}$ Program Studi Akuntansi, Fakultas Ekonomi, Universitas PGRI Adi Buana Surabaya \\ E-mail : rinafariana@unipasby.ac.id
}

\begin{abstract}
ABSTRAK
Salah satu penggerak utama laju perekonomian desa adalah adanya Badan Usaha Milik Desa (BUMDes) yang dikelola sepenuhnya oleh mayarakat desa. Desa Kebotunggul memiliki beberapa potensi yang dapat dikembangkan dan dikellola sehingga bermanfaat bagi penduduk masyarakat desa. Adapun potensi Desa Kebontunggul meliputi peternakan unggas, perikanan lele, industri mebel, industri rumah tagga (keripik tortila, jamur dan jamu) dan wisata edukasi. Banyaknya potensi yang terdapat di Desa Kebontunggul terutama sebagai desa wisata sebaiknya diiringi dengan pengelolaan yang baik sehingga bisa memberikan nilai manfaat yang lebih khususnya bagi perekonomian masyarakat sekitar. Pengelolaan dan pembinaan tersebut dapat melalui Badan Usaha Milik Desa (BUMDes). Permasalahan utama yang dihadapi oleh mitra adalah mengenai manajemen pengelolaan keuangan pelaku usaha dan BUMDes. Sumber daya manusia pengelola BUMDes Desa Kebontunggul sebagai penggerak perekonomian desa sangat kurang memadai, hal ini dibuktikan dengan kurangnya kegiatan administrasi yang dilakukan oleh BUMDes Desa Kebontunggul seperti pembuatan dokumen, pengarsipan, pembukuan keuangan dan penggunaan alat elektronik seperti komputer termasuk dalam melakukan pendampingan terhadap pelaku usaha di desa. Hal ini menyebabkan pelaporan BUMDes tidak bisa menghasilan laporan secara benar yang diikuti oleh pelaku usaha yang ada di desa. Berdasarkan permasalahan tersebut, maka perlu adanya pelatihan pembukuan sederhana sebagai upaya peningkatan kinerja keuangan BUMDes pelaku usaha. Hasil dari kegiatan pengabdian ini yaitu mitra telah mampu melakukan pembukuan sederhana, menentukan HPP yang sesuai dan sampai penyusunan laporan keuangan dengan baik dan rutin sehingga mitra bisa menjadi desa percontohan.
\end{abstract}

Kata kunci : BUMDes, pembukuan sederhana, desa wisata

\begin{abstract}
One of the main drivers of the pace of the village economy is the existence of Badan Usaha Milik Desa (BUMDes) which are fully managed by village communities. Kebotunggul village has several potentials that can be developed and managed so that it is beneficial for villagers. The potential of Kebontunggul Village includes poultry farming, catfish fisheries, furniture industry, home made industry (tortilla chips, mushrooms and herbs) and educational tourism. The great potential contained in Kebontunggul Village especially as a tourism village should be accompanied by good management so that it can provide more benefits especially to the economy of the surrounding community. Management and guidance can be through the Badan Usaha Milik Desa (BUMDes). The main problem faced by partners is regarding the financial management of business actors and BUMDes. The human resources of the Kebontunggul Village BUMDes as the drivers of the village economy are very inadequate, this is evidenced by the lack of administrative activities carried out by the Kebontunggul BUMDes such as document making, filing, financial accounting and the use of electronic devices such as computers, including in assisting businesses in village. This causes BUMDes reporting to not produce true reports that are followed by business actors in the village. Based on these problems, it is necessary to have simple accounting training as an effort to improve the
\end{abstract}


financial performance of BUMDes businesses. The results of this community service activity are that partners have been able to do simple accounting, determine the appropriate COGS and to prepare financial reports properly and routinely so that partners can become pilot villages.

Keywords : BUMDes, simple accounting, tourism village

\section{PENDAHULUAN}

Pengabdi memaparkan kondisi mitra, meliputi kewilayaan berupa kondisi eksisting sumber daya usaha kecil/menengah, masyarakat atau kebutuhan mitra yang menjadi fokus pelaksanaan kegiatan pengabdian kepada masyarakat (PPM). Untuk UMKM, dipaparkan juga upaya-upaya yang pernah diterimakan pihak lain kepada usaha kecil/menengah, masyarakat atau PT. Akhir penjelasan pengabdi menyampaikan tujuan dari kegiatan pengabdian yang dilaksanakan.

Usaha Mikro, Kecil dan Menengah (UMKM) merupakan pelaku kunci keberhasilan dalam pembangunan ekonomi nasional. Pelaku UMKM setiap tahunnya mengalami peningkatan, berdasarkan data Badan Pusat Statistik pada tahun 2012 UMKM di Jawa Timur mengalami kenaikan menjadi 6.800.000 pelaku UMKM dan di tahun 2018 mengalami kenaikan menjadi 9.590.000 pelaku UMKM. Berdasarkan data Dinas Koperasi dan UMKM, peningkatan jumlah UMKM salah satunya yaitu UKM Mojokerto yang mencapai 155.354 unit pelaku. Dengan semakin banyaknya pelaku UMKM setiap tahunnya, maka persaingan produk UMKM dan risiko usaha juga akan mengalami kenaikan. Pelaku usaha UMKM diharapkan dapat menganalisis risiko yang timbul dari usahanya sehingga pelaku UMKM dapat mengelola dan mengkontrol resiko-resiko yang akan timbul dalam kegiatan usahanya. Sudaryanto dan Hanim (2002) menjelaskan bahwa salah satu faktor penghambat dalan pemberdayaan UMKM yaitu kualitas manajemen yang sangat rendah.

Desa Kebotunggul memiliki beberapa potensi yang dapat dikembangkan dan dikelelola sehingga bermanfaat bagi penduduk masyarakat desa. Adapun potensi Desa Kebontunggul meliputi peternakan uanggas, perikanan lele, industri mebel, industri rumah tagga (keripik tortila, jamur dan jamu) dan wisata edukasi. Untuk mewujudkan desa yang memiliki kekuatan ekonomi, budaya serta memiliki kepedulian tinggi terhadap pembangunan serta pemberdayaan desa, Desa Kebontunggul berupaya untuk mewujudkan desa wisata dan menonjolkan kearifan lokal serta keindahan alam yang dimiliki melalui Wisata Edukasi Terpadu "Lembah Mbencirang"

Banyaknya potensi yang terdapat di Desa Kebontunggul sebaiknya diiringi dengan pengelolaan yang baik sehingga bisa memberikan nilai manfaat yang lebih khususnya bagi perekonomian masyarakat sekitar. Pengelolaan dan pembinaan tersebut dapat melalui Badan Usaha Milik Desa (BUMDes). Permasalahan utama yang dihadapi oleh mitra adalah mengenai manajemen pengelolaan BUMDes. Sumber daya pengelolaan BUMDes menjadi hal yang utama guna menunjang keberhasilan pengelolaan BUMDes Desa Kebontunggul dan pelaku usaha yang lain. Sumber daya manusia pengelola BUMDes Desa Kebontunggul sangat kurang memadai, hal ini dibuktikan dengan 
kurangnya kegiatan administrasi yang dilakukan oleh BUMDes Desa Kebontunggul seperti pembuatan dokumen, pengarsipan, pembukuan keuangan dan penggunaan alat elektronik seperti komputer. Hal ini menyebabkan pelaporan BUMDes tidak bisa menghasilan laporan secara benar yang diikuti oleh pelaku usaha lainnya yang ada di desa.

Sebagai pengelola keuangan desa serta penggerak perekonomian desa, BUMDes juga bertanggjngjawab terhadap pendampingan terhadap pelaku usaha, sehingga perlu adanya penguatan terhadap BUMDes dan pelaku usaha mengenai pembukuan sederhana. Berdasarkan penjelasan permasalahan tersebut, maka perlu adanya pelatihan pembukuan sederhana sebagai upaya peningkatan kinerja keuangan terhadap pelaku usaha dengan BUMDes sebagai lembaga yang mendukung dan melakukan pendampingan terhadap pelaku usaha nantinya. Pengabdian yang dilakukan tim Fakultas Ekonomi Prodi Akuntansi Universitas PGRI Adi Buana Surabaya bertujuan untuk membantu BUMDes dalam melakukan pelatihan pembukuan sederhana terhadap pelaku Usaha Mikro, Kecil dan Menengah Desa Kebontunggul Kecamatan Gondang Kabupaten Mojokerto.

\section{METODE PELAKSANAAN}

Persoalan yang dihadapi oleh UMKM di desa Kebontunggul Kecamatan Gondang Kabupaten Mojokerto adalah kurangnya pengetahuan mengenai pencatatan transaksi dan pelaporan keuangan serta penyusunan HPP yang benar, sehingga tim memberikan solusi dengan memberikan penyuluhan, pelatihan dan pendampingan kepada pelaku UMKM mengenai pembukuan sederhana dengan metode tata buku tunggal sampai pada penyusunan laporan keuangan menurut SAK-ETAP, serta bagaimana menghitung HPP yang benar agar tidak terjadi kekeliruan dalam menentukan harga jual produk. Metode pelaksanaan kegiatan pengabdian ini antara lain :

1. Penyuluhan

Sebelum tim melakukan pelatihan mengenai pembukuan sederhana dengan metode tata buku tunggal, tim terlebih dahulu memberikan pemahaman mengenai pentingnya penyusunan laporan keuangan bagi UMKM yang baik dan benar. Tim memberikan pemahaman mengenai tujuan penyusunan laporan keuangan dan menjelaskan siklus pembuatan laporan keuangan UMKM, penghitungan HPP serta penentuan harga jual. Tujuan laporan keuangan adalah memberikan informasi mengenai posisi keuangan, kinerja keuangan dan arus kas entitas yang bermanfaat bagi sebagian besar kalangan pengguna laporan keuangan untuk membuat keputusan ekonomi (Diana dan Setiawati, 2017)

2. Praktek

Langkah selanjutnya setelah dilakukan penyuluhan adalah melakukan praktek terkait pembukuan sederhana dengan metode tata buku tunggal sampai pada pelaporan keuangan. Dalam praktek ini tim terlebih dahulau memberikan contoh pembukuan sederhana mulai dari pencatatan transaksi menggunakan metode tata buku tunggal, penyusunan laporan keuangan maupun penghitungan HPP dan 
penentuan harga jual. Langkah berikutnya tim menyediakan kertas kerja bagi mitra untuk mencatat transaksi bisnisnya maupun kertas kerja untuk membuat laporan keuangan dan melakukan penghitungan HPP serta penentuan harga jual. Menurut Suhardiyah, dkk (2017) sebelum menentukan harga jual suatu produk atau jasa, perusahaan mengumpulkan terlebih dahulu berapa biaya produksi yang dibutuhkan.

3. Pendampingan

Setelah kedua tahap dilakukan, tahap terakhir yang dilakukan oleh tim pengabdian yaitu pendampingan kepada pelaku UMKM di Desa Kebontungul Kecamatan Gondang Kabupaten Mojokerto. Pendampingan dilakukan oleh tim pengabdian untuk mengetahui keberhasilan program yang ditawarkan. Proses pendampingan dilakukan dengan cara diskusi antara tim dengan mitra. Hal ini dilakukan untuk mengetahui hambatan-hambatan yang dialami oleh mitra selama melakukan pembukuan sederhana mulai dari pencatatan transaksi dengan metode tata buku tunggal, penyusunan laporan keuangan maupun penghitungan HPP dan penentuan harga jual sehingga tim dapat memberikan solusi kepada mitra.

\section{HASIL DAN PEMBAHASAN}

Kegiatan pengabdian kepada pelaku UMKM di Desa Kebontungggul Kecamatan Gondang Kabupaten Mojokerto dilakukan selama 1 (satu) bulan. Hasil dalam kegiatan pengabdian ini adalah pencatatan transaksi menggunakan metode tata buku tunggal. Menurut Tunggal (1997) transaksi yang dilakukan perusahaan kecil dan menengah pada dasarnya sama dengan transaksi perusahaan besar. Seandainya ada perbedaan hanyalah terletak dalam jumlah dan besarnya transaksi. Dalam tata buku tunggal transaksitransaksi yang dicatat dalam buku-buku hariann tidak diolah lebih lanjut dalam bukubuku lain (Tunggal, 1997). Artinya dalam tata buku tunggal tidak ada pencatatan dalam buku besar. Berbeda dengan tata buku berpasangan, pada tata buku tunggal dalam penyusunan neraca dan laporan laba rugi tidak di dasarkan buku besar, namun berdasarkan catatan-catatan dalam buku harian dan buku lainnya. Metode ini menjadi lebih sederhana dan cocok untuk UMKM, namun pada metode tidak secara kontinu mencatat dan mengikuti perubahan-perubahan dalam susunan harta, utang dan modal perusahaan. Hal ini tidak menjadi masalah pada UMKM karena jumlah dan transaksi pada UMKM tidak besar seperti pada perusahaan besar.
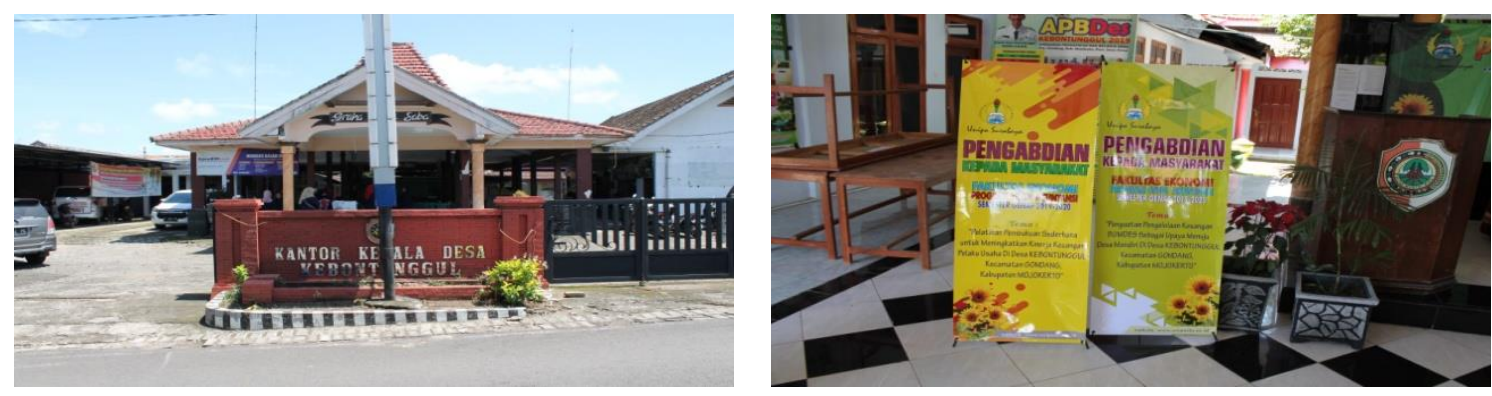

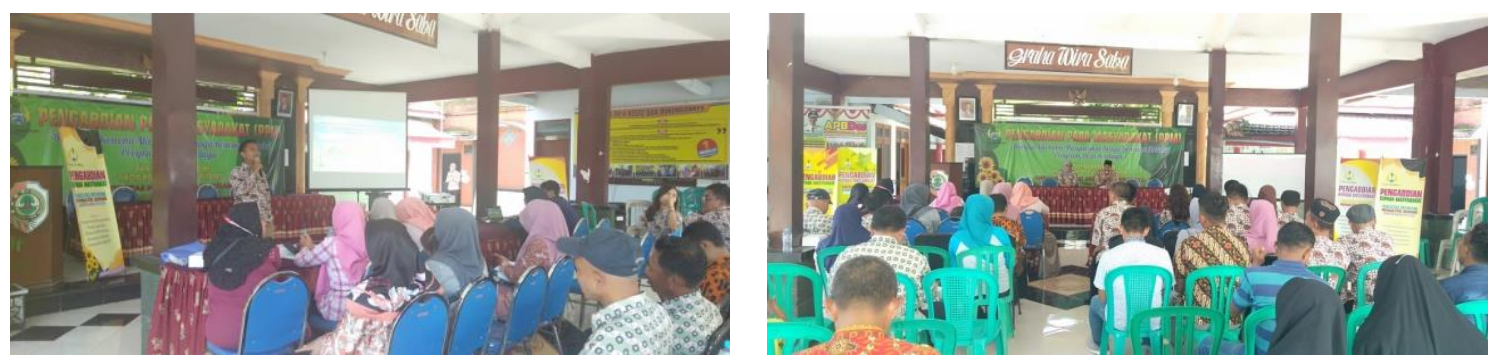

Gambar 1. Pelatihan Pembukuan Sederhana di Desa Kebontunggul, Kecamatan Gondang, Mojokerto

Transaksi-transaksi pengeluaran uang, penerimaan uang, penjualan dan pembelian barang dan jasa secara kredit serta transaksi non kas lainnya dalam tata buku tunggal dicatat dalam buku harian dan buku pembantu. Adapun hasil pelatihan ini adalah penggunaan buku harian dan buku pembantu, berikut contoh hasil buku harian:

a) Buku Pengeluaran Kas

Tabel 1. Buku Pengeluaran Kas Kripik Tortila Desa Kebontunggul (dalam ribuan $\mathrm{Rp}$ )

\begin{tabular}{llrrrr}
\hline Tgl & Keterangan & Ref & Utang & Pembelian & \multicolumn{2}{c}{ Lain-lain } & Saldo \\
\cline { 1 - 1 } & $\begin{array}{l}\text { Pembelian } \\
\text { bumbu }\end{array}$ & 100 & Perk & Jumlah & \\
\hline
\end{tabular}

b) Buku Penerimaan Kas

Tabel 2. Buku Penerimaan Kas Kripik Tortila Desa Kebontunggul (dalam ribuan $\mathrm{Rp}$ )

\begin{tabular}{|c|c|c|c|c|c|c|c|}
\hline \multirow{2}{*}{ Tgl } & \multirow{2}{*}{ Keterangan } & \multirow{2}{*}{ Ref } & \multirow{2}{*}{ Piutang } & \multirow{2}{*}{ Penjualan } & \multicolumn{2}{|c|}{ Lain-lain } & \multirow{2}{*}{ Saldo } \\
\hline & & & & & Perk & Jumlah & \\
\hline 20 & Penjualan & & & 300 & & & 300 \\
\hline
\end{tabular}

c) Buku Penjualan

Tabel 3. Buku Penjualan Kripik Tortila Desa Kebontunggul (dalam ribuan $\mathrm{Rp}$ )

\begin{tabular}{llrl}
\hline Tgl & Keterangan & Ref & Jumlah \\
\hline 24 & Penjualan Kredit kepada Pak Darmin & & 200 \\
\hline
\end{tabular}

d) Buku Pembelian

Tabel 4. Buku Pembelian Kripik Tortila Desa Kebontunggul (dalam ribuan $\mathrm{Rp}$ )

\begin{tabular}{llrl}
\hline Tgl & Keterangan & Ref & Jumlah \\
\hline 8 & Pembelian Kredit kepada Toko Rizki & & 550 \\
\hline
\end{tabular}


e) Buku Memorial

Tabel 5. Buku Memorial Kripik Tortila Desa Kebontunggul

(dalam ribuan $\mathrm{Rp}$ )

\begin{tabular}{llll}
\hline Tgl & Keterangan & Ref & Jumlah \\
\hline & - & & \\
\hline
\end{tabular}

Selain buku harian di atas, sebagai dasar penyusunan laporan keuangan, mitra juga diajarkan menyusun buku pembantu. Tujuannya adalah memudahkan dalam (Setiawan,2009), berikut macam dari buku pembantu:

a) Buku Piutang

b) Buku Utang

c) Buku Persediaan

Setelah mitra mampu menyusun buku harian dan buku pembantu, mitra juga diberikan pelatihan penyusunan laporan keuangan yang terdiri dari neraca dan laporan laba rugi. Berikut contoh hasil neraca pelaku usaha kripik tortila di Desa Kebontunggul:

Tabel 5. Neraca Kripik Tortila Desa Kebontunggul (dalam ribuan $\mathrm{Rp}$ )

\begin{tabular}{lrlr}
\hline AKTIVA & & PASIVA \\
Aktiva Lancar & & $\underline{\text { Utang Lancar }}$ & \\
Kas & 480 & Utang Dagang & 750 \\
Piutang & 640 & & \\
Persediaan & & $\underline{\text { Utang Jangka Panjang }}$ & 700 \\
Aktiva Tetap & 34.600 & EKUITAS & \\
Tanah dan bangunan & 950 & Modal & $\underline{35.660}$ \\
Peralatan & 37.110 & & 37.110 \\
& & & \\
\hline
\end{tabular}

Selama kegiatan pelatihan pembukuan sederhana, tim tidak hanya menyediakan buku akuntansi yang nanti akan digunakan mitra untuk mencatat setiap transaksinya, tetapi tim pengabdian juga melakukan pelatihan dengan memanfaatkan teknologi sederhana yang tidak menyulitkan pelaku usaha kripik tortila dan pelaku usaha lainnya sehingga pelaku usaha dapat memanfaatkan teknologi tersebut secara maksimal. Adapun pemanfaatan teknologi melalui Microsoft excel.

Selanjutnya tim melakukan pelatihan penghitungan HPP dan penentuan harga jual yang benar. Bagi produsen, sebelum menentukan harga barang yang akan dijual kepada konsumen, maka ia perlu mengetahui terlebih dahulu harga pokok produksinya (HPP). HPP merupakan keseluruhan harga dari harga baku, pengolahan, hingga barang jadi. HPP juga dapat dipahami sebagai harga beli dari supplier. Setelah diketahui HPP, kemudian ditentukan keuntungan yang diinginkan (Kuswadi, 2005).

Rumus HPP:

HPP : Material + Labour + Overhead + Inventori Awal - Inventori Akhir 
Keterangan:

Material = bahan baku

Labour = tenaga kerja

Overhead = biaya produksi rutin

Inventori $=$ sisa produksi

Diketahuinya HPP dan keuntungan yang diinginkan, maka produsen dapat menentukan harga jual produknya agar dapat menutup seluruh biaya HPP dan memperoleh keuntungan yang diinginkan.

\section{DAMPAK DAN MANFAAT KEGIATAN}

Selama 1 bulan, mitra telah menyusun pembukuan sederhana meliputi buku penerimaan dan pengeluaran kas, laporan penjualan dan pembelian, buku memorial, buku pembantu utang dan piutang, buku persediaan serta neraca dan laporan laba-rugi. Selain itu UMKM juga telah mampu menghitung HPP dan penentuan harga jual yang benar.

\section{SIMPULAN}

Setelah dilakukannya pelatihan dan pendampingan kepada pelaku usaha Desa Kebontunggul, dapat disimpulkan bahwa mitra telah mampu melakukan pembukuan sederhana dengan metode tata buku tunggal sampai pada penyusunan laporan keuangan dan menghitung HPP dan serta penentuan harga secara mandiri. Adapun saran kegiatan ini adalah mitra dapat konsisten melakukan pencatatan dan pelaporan akuntansi, serta penghitungan HPP sehingga mitra dapat menentukan harga dengan benar.

\section{UCAPAN TERIMA KASIH}

Tim pengabdian Fakultas Ekonomi mengucapkan terima kasih atas pendanaan internal dari Lembaga Penelitian dan Pengabdian Masyarakat Universitas PGRI Adi Buana Surabaya yang telah diberikan kepada tim pengabdian, sehingga programprogram yang ditawarkan oleh tim kepada mitra (pelaku usaha Desa Keboontunggul) berjalan dengan lancar serta mitra dapat memperoleh manfaat atas program yang ditawarkan yang dilakukan oleh tim pengabdian.

\section{DAFTAR PUSTAKA}

Diana, Anastasia dan Lilis Setiawati. (2017). Akuntansi Keuangan Menengah:Berdasarkan Standar Akuntansi Keuangan Terbaru. Yogyakarta: Andi Offset

Kuswadi. (2005). Akuntansi Keuangan. Jakarta: Salemba Empat.

Setiawan, Temy. (2009). Mahir Akuntansi : Perusahaan Dagang. Jakarta : PT. Bhuana Ilmu Populer.

Sudaryanto dan Hanim,Anifatul. (2002). Evaluasi kesiapan UKM Menyongsong Pasar Bebas Asean (AFTA) : Analisis Perspektif dan Tinjauan Teoritis. Jurnal Ekonomi Akuntansi dan Manajemen, Vol 1 No 2, Desember 2002 
Suhardiyah, Martha, Rina Fariana dan Aristha Purwanthari Sawitri. (2017). Akuntansi Biaya: Suatu Konsep Menghitung Biaya Produk. Surabaya: Adi Buana University Press

Tunggal, Widjaja Amin. (1997). Akuntansi Perusahaan Kecil dan Menengah. Jakarta: PT Rineka Cipta. 